\title{
Staphylococcus aureus Panton-Valentine leukocidin directly targets mitochondria and induces Bax-independent apoptosis of human neutrophils
}

\author{
Anne-Laure Genestier, ${ }^{1}$ Marie-Cécile Michallet, ${ }^{2}$ Gilles Prévost, ${ }^{3}$ Gregory Bellot, ${ }^{4}$ \\ Lara Chalabreysse, ${ }^{5}$ Simone Peyrol, ${ }^{6}$ Françoise Thivolet, ${ }^{5}$ Jerome Etienne, ${ }^{1}$ Gérard Lina, ${ }^{1}$ \\ François M. Vallette, ${ }^{4}$ François Vandenesch, ${ }^{1}$ and Laurent Genestier ${ }^{7}$ \\ ${ }^{1}$ Centre National de Référence des Staphylocoques, INSERM E0230, Lyon, France. ${ }^{2}$ INSERM U503, Biosciences Lyon Gerland, Lyon, France. \\ ${ }^{3}$ Laboratoire de Physiopathologie et d'Antibiologie des Infections Bactériennes Emergentes et Nosocomiales-EA 3432, \\ Institut de Bactériologie de la Faculté de Médecine-Hôpitaux Universitaires de Strasbourg, Strasbourg, France. ${ }^{4}$ INSERM/Université de Nantes UMR 601, \\ Nantes, France. ${ }^{5}$ Department of Pathology, Hôpital Louis Pradel, BP Lyon Montchat, Lyon, France. ${ }^{6}$ Centre Commun d'Imagerie Laennec, \\ Lyon, France. 7 INSERM U404, Biosciences Lyon Gerland, Lyon, France.
}

\begin{abstract}
Panton-Valentine leukocidin (PVL) is a pore-forming toxin secreted by Staphylococcus aureus that has recently been associated with necrotizing pneumonia. In the present study, we report that in vitro, PVL induces polymorphonuclear cell death by necrosis or by apoptosis, depending on the PVL concentration. PVL-induced apoptosis was associated with a rapid disruption of mitochondrial homeostasis and activation of caspase-9 and caspase-3, suggesting that PVL-induced apoptosis is preferentially mediated by the mitochondrial pathway. Polymorphonuclear cell exposure to PVL leads to mitochondrial localization of the toxin, whereas Bax, 1 of the 2 essential proapoptotic members of the Bcl-2 family, was still localized in the cytosol. Addition of PVL to isolated mitochondria induced the release of the apoptogenic proteins cytochrome $c$ and Smac/ DIABLO. Therefore, we suggest that PVL, which belongs to the pore-forming toxin family, could act at the mitochondrion level by creating pores in the mitochondrial outer membrane. Furthermore, LukS-PV, 1 of the 2 components of PVL, was detected in lung sections of patients with necrotizing pneumonia together with DNA fragmentation, suggesting that PVL induces apoptosis in vivo and thereby is directly involved in the pathophysiology of necrotizing pneumonia.
\end{abstract}

\section{Introduction}

Staphylococcus aureus necrotizing pneumonia, which occurs predominantly in young immunocompetent patients, has recently been described as a novel clinical entity $(1,2)$. This pathology is associated with leukopenia, hemoptysis, and extensive necrosis of the respiratory epithelium of the bronchi and the alveolar septa of the lung parenchyma (1). We also found that these cases were always associated with $S$. aureus strains producing an otherwise very infrequent exotoxin called Panton-Valentine leukocidin (PVL) (1). Indeed PVL was recently found to be present at a very low prevalence $(0.6 \%)$ in healthy carriers but was present in a significantly high number of strains $(38.9 \%)$ that cause abscesses and arthritis $(3,4)$.

PVL is a staphylococcal synergohymenotropic exotoxin belonging to the pore-forming toxin family (5-7). In vitro, PVL has been shown to induce lysis of host defense cells such as human polymorphonuclear neutrophils (PMNs), monocytes, and macrophages (8). Pore formation requires the presence of the 2 components of the

Nonstandard abbreviations used: $\mathrm{CBz}$, benzyloxycarbonyl; $\Delta \psi \mathrm{m}$, mitochondrial transmembrane potential; MnSOD, manganese superoxidase dismutase; $n$ PVL, native PVL; PBL, peripheral blood lymphocyte; PMN, polymorphonuclear neutrophil; PVL, Panton-Valentine leukocidin; rLukF-PV, recombinant LukF-PV; rLukS-PV, recombinant LukS-PV; rPVL, recombinant PVL; TEM, transmission electron microscopy; zVAD-fmk, CBz-Val-Ala-DL-Asp(Ome)-fluoromethylketone.

Conflict of interest: The authors have declared that no conflict of interest exists.

Citation for this article: J. Clin. Invest. 115:3117-3127 (2005).

doi:10.1172/JCI22684. toxin, LukS-PV and LukF-PV. This pore is an octameric $\beta$-barrel molecular complex (9) perpendicular to the plane of the cell membrane, similar to that made by $S$. aureus $\alpha$-toxin (10). Sublytic concentrations of purified PVL induce pronounced histamine release from human basophils and stimulate human neutrophils to release enzymes ( $\beta$-glucuronidase and lysozyme), chemotactic components (leukotriene-B4 and IL-8), and oxygen metabolites (10-14).

Two major mechanisms of eukaryotic cell death have been identified, namely necrosis and apoptosis. Necrotic cell death has classically been considered as a passive process resulting from physical or chemical injury. In contrast, cells undergoing apoptosis play an active role in their own demise: extracellular stimuli or genetic programming activates a cascade of intracellular events resulting in morphological and biochemical alterations. Apoptosis has already been described in monocytes and PMNs exposed to $S$. aureus $\alpha$-toxin and Fusobacterium necrophorum leukotoxin, respectively (15, 16). PVL-sensitive target cells, including PMNs, macrophages, and the promyelocytic cell line HL- $60(8,17,18)$ are thought to undergo osmotic lysis secondary to pore formation in the cell membrane. This process would be consistent with necrosis. Although PVL has potent membrane-disturbing and cytolytic activities in vitro, the mechanisms by which it exerts its lethal effects on target cells, particularly on the first line of host defense cells such as neutrophils, and the sequence of events in the overall cytotoxicity are not known. Furthermore, in other clinical situations such as fulminant hepatitis (19), the apparent predominance of necro- 

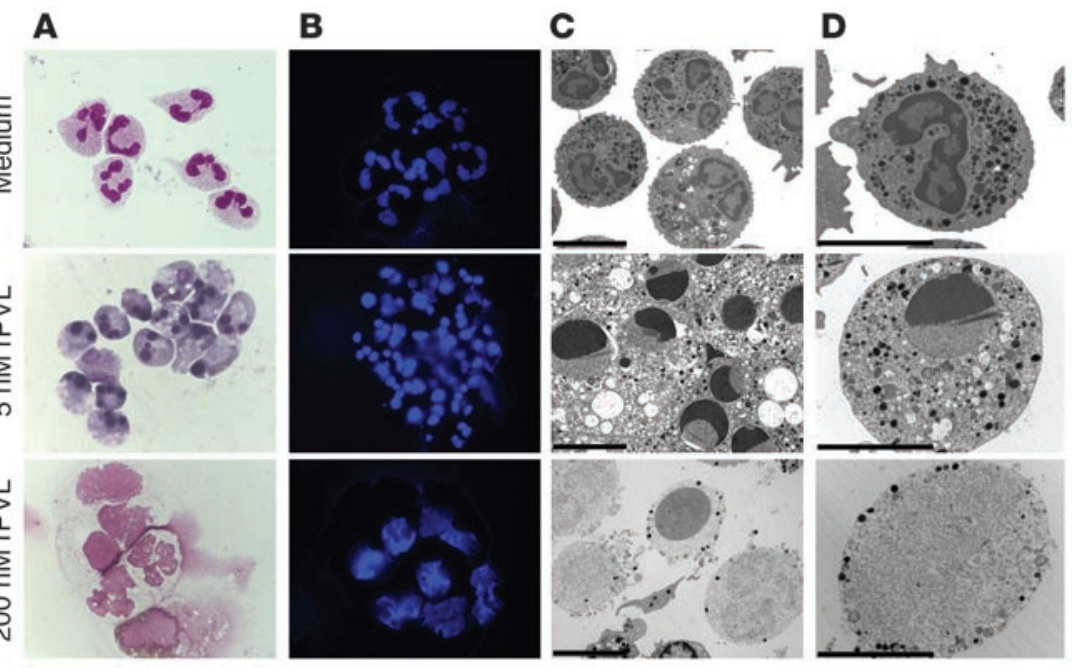

\begin{abstract}
Figure 1
PMN apoptosis and necrosis as a function of the rPVL concentration. PMNs were incubated with medium for 6 hours, with $5 \mathrm{nM}$ rPVL for 6 hours, or with $200 \mathrm{nM}$ rPVL for 1 hour. PMNs were then cytospun on glass coverslips and observed after either May-Grünwald/Giemsa staining $(\mathbf{A})$ or Hoechst 33342 staining (B) for nuclear morphology or prepared for TEM (C and D). Scale bars: $20 \mu \mathrm{m}$.
\end{abstract}

sis has been shown to be actually secondary to apoptosis. Hence, the mechanisms by which PVL causes injury to host tissues and potentially to peripheral blood cells during the course of infection are not clearly established, and the role of necrosis versus apoptosis in the pathogenesis of PVL-associated infections remains to be defined. The focus of the present study was to characterize the biological effects of $S$. aureus PVL on human peripheral PMNs in relation to the possible involvement of this toxin in necrotizing pneumonia pathogenesis.

\section{Results}

PVL-induced PMN necrosis versus apoptosis is concentration dependent. Recombinant PVL (rPVL) cytotoxicity for PMNs was assessed at various concentrations. Recombinant LukS-PV (rLukS-PV) and recombinant LukF-PV (rLukF-PV) were used together at equimolar concentrations of $5 \mathrm{nM}$ or $200 \mathrm{nM}$. The morphology of rPVLtreated PMNs was examined on cytospin preparations stained with either May-Grünwald/Giemsa or Hoechst 33342. After only 1 hour of treatment with $200 \mathrm{nM}$ rPVL, PMNs showed typical features of necrosis, with swelling and no chromatin condensation. In contrast, 6 hours of treatment with $5 \mathrm{nM}$ rPVL induced a typical apoptotic morphology, including rounding of cells and nuclei, and pronounced chromatin condensation (Figure 1, A and B).

These morphologic observations were confirmed by transmission electron microscopy (TEM) ultrastructural examination of rPVL-treated and -untreated PMNs. After 6 hours of culture without rPVL, the PMN ultrastructure was normal (multilobular nucleus, numerous primary and secondary granules). In contrast, chromatin condensation and cell rounding were observed after treatment with $5 \mathrm{nM} \mathrm{rPVL}$ for 6 hours. In these conditions, more than $80 \%$ of PMNs had pyknotic nuclei, with or without loss of nuclear membrane continuity, and cytoplasmic hypervacuolation. Finally, PMNs treated with 200 nM rPVL for 1 hour were predominantly necrotic, with loss of cell membrane integrity and the release of cellular contents. At this concentration, a large number of PMNs did not contain nuclear material (Figure 1, C and D).

Phosphatidylserine translocation occurs in many cell types undergoing apoptosis. To determine whether PVL-mediated PMN cytotoxicity involved similar perturbation in cell membrane asymmetry, we measured phosphatidylserine translocation with annexin $\mathrm{V}$ in the presence of propidium iodide to evaluate the cell mem- brane integrity. Cells treated with $5 \mathrm{nM}$ rPVL or $0.5 \mathrm{nM}$ native PVL (nPVL) for 6 hours exhibited a typical apoptotic profile, with annexin $\mathrm{V}$ binding without propidium iodide staining, whereas treatment with rLukF-PV or rLukS-PV alone did not induce significant apoptosis (Figure 2A). In contrast, PMNs treated with $200 \mathrm{nM}$ rPVL or $5 \mathrm{nM}$ nPVL for 1 hour stained positive for both propidium iodide and annexin $\mathrm{V}$ and were therefore necrotic (Figure 2A).

Finally, we tested the apoptotic effect of culture supernatant of the S. aureus isogenic strains RN6390 (luk-PV -); RN6390 lysogenized with $\Phi$ SLT phage carrying $l u k-P V$; or a deleted luk-PV $(\Delta l u k-P V)$ mutant of $S$. aureus RN6390 lysogenized with SSLT phage. Whereas PMNs treated with culture supernatant from RN6390 lysogenized with $\Phi$ SLT phage exhibited apoptotic features with externalization of phosphatidylserine and decrease in the mitochondrial transmembrane potential $(\Delta \psi \mathrm{m})$, treatment with supernatant from the isogenic strain deleted for $l u k-P V$ did not trigger apoptosis in PMNs (Figure 2B).

Kinetics of plasma membrane and mitochondrial alterations during PVL-induced PMN apoptosis. PMN apoptosis induced by $5 \mathrm{nM} \mathrm{rPVL}$ was maximal at 6 hours, reaching a plateau around $65 \%$, whereas spontaneous apoptosis increased slightly after 8 hours of culture without rPVL (Figure 3A).

To determine whether mitochondria were affected by PVL, we first measured the decrease in the $\Delta \psi \mathrm{m}$ after rPVL treatment. rPVL markedly decreased the $\Delta \psi \mathrm{m}$ after only 5 minutes of incubation, whereas the $\Delta \psi \mathrm{m}$ was still maintained for 30 minutes in $80 \%$ of untreated PMNs (Figure 3B). This drop in $\Delta \psi \mathrm{m}$ was associated with a rapid lost at 5 minutes of mitochondrial integrity as visualized by the diffuse staining of MitoTracker in rPVL-treated PMNs (Figure 3C). In contrast, control PMNs cultured for 30 minutes showed localized mitochondrial MitoTracker staining with a distinct tubular shape. Furthermore, ROS accumulation was detected in $60 \%$ of rPVL-treated PMNs as early as 2 hours and in only $25 \%$ of control PMNs after up to 12 hours (Figure 3D).

Caspases are involved in PVL-induced PMN apoptosis. The broad-spectrum caspase inhibitor benzyloxycarbonyl-Val-Ala-DL-Asp(Ome)fluoromethylketone [CBz-Val-Ala-DL-Asp(Ome)-fluoromethylketone; zVAD-fmk] inhibited both spontaneous and rPVL-induced apoptosis, demonstrating that caspases are involved in PVLinduced PMN apoptosis (Figure 4B). We then studied the effect of zVAD-fmk on PMN morphology after 6 hours of treatment with 
A

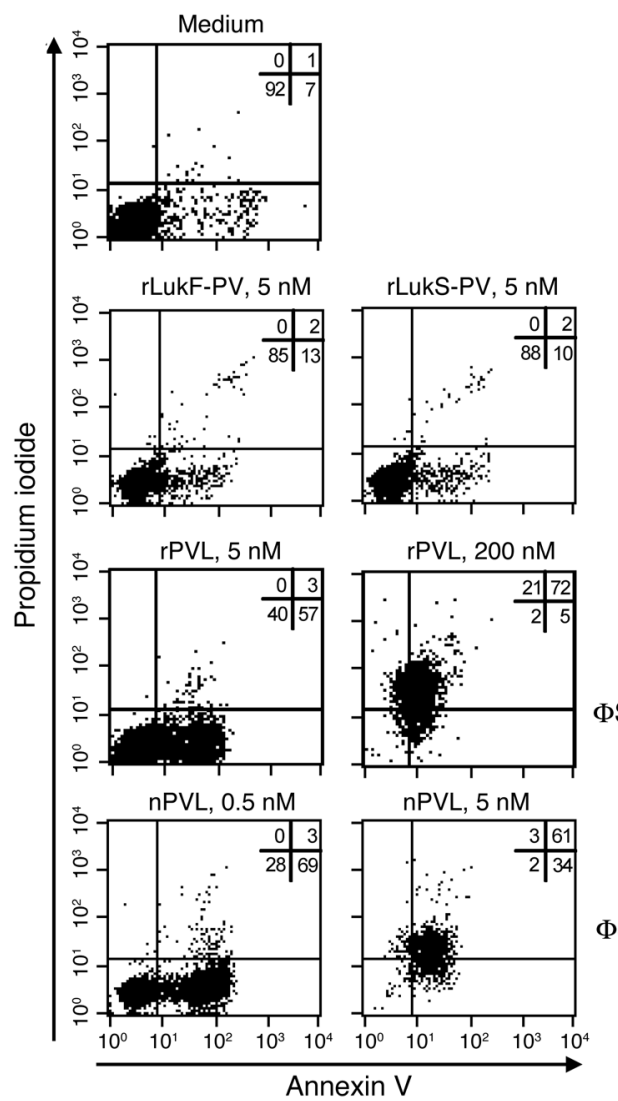

B

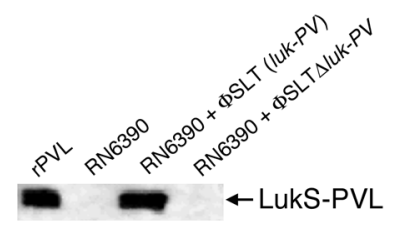

Medium
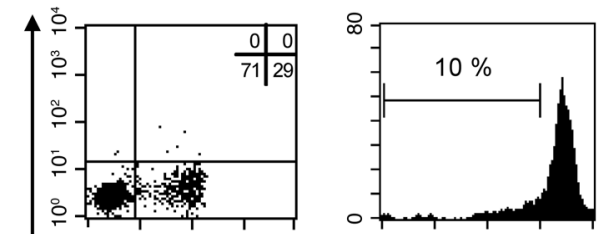

RN6390

$\mathrm{RN} 6390+$ SSLT (luk-PV)

$\mathrm{RN} 6390+$ ФSLT $\Delta l u k-P V$
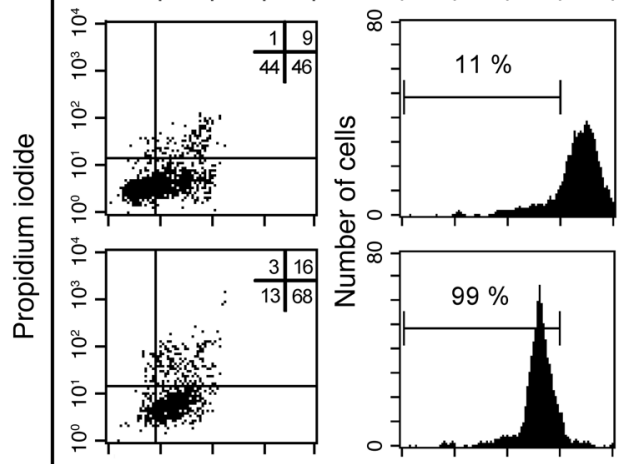
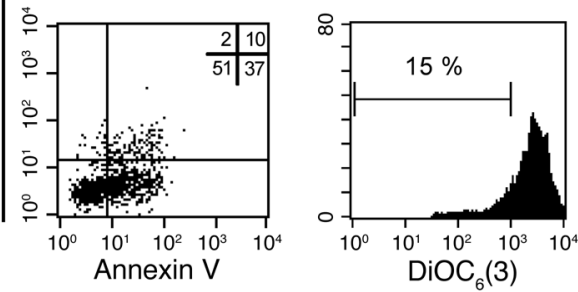

Figure 2

PMN apoptosis is induced by native as well as rPVL and culture supernatant of the S. aureus isogenic strains RN6390 expressing PVL. (A) PMNs were incubated with rLukF-PV, rLukS-PV, rPVL, or $\mathrm{nPVL}$ at various concentrations. Cell death was measured by surface binding of annexin $\mathrm{V}$ after 6 hours when treated with $5 \mathrm{nM}$ rLukF-PV, $5 \mathrm{nM}$ rLukS-PV, $5 \mathrm{nM}$ rPVL, or $0.5 \mathrm{nPVL}$ and after 1 hour when treated with $200 \mathrm{nM}$ rPVL or 5 $\mathrm{nM}$ nPVL. (B) Culture supernatants of the $S$. aureus isogenic strains RN6390 (luk-PV -); RN6390 lysogenized with $\Phi S L T$ phage carrying luk-PV; or a deleted luk-PV ( $\Delta /$ luk-PV) mutant of $S$. aureus RN6390 lysogenized with $\Phi S L T$ phage or rPVL were separated on 12\% SDS-PAGE followed by Western blotting with anti-LukS-PV 1C12 mAb. PMNs were treated with a 1:2,000 dilution of culture supernatant of the S. aureus isogenic strains RN6390 (luk-PV -); RN6390 lysogenized with $\Phi S L T$ phage carrying luk-PV; or a deleted luk-PV ( $\Delta / u k-P V)$ mutant of $S$. aureus RN6390 lysogenized with $\Phi S L T$ phage. PMN apoptosis was monitored by measuring the decrease in $\Delta \psi \mathrm{m}$ after 5 minutes and the surface binding of annexin $V$ after 6 hours. Data are from 1 of 3 independent experiments that gave similar results.

$5 \mathrm{nM}$ rPVL. Chromatin condensation was inhibited by zVAD-fmk, but PMNs did not recover their normal morphology, as visualized by the large cytoplasmic protrusions (Figure 4A). The effect of zVAD-fmk on nuclear morphology was confirmed by inhibition of rPVL-induced DNA fragmentation measured by Apostain. Indeed, in the presence of PVL, more than $60 \%$ of cells exhibited DNA fragmentation, whereas this proportion fell to only $1 \%$ when cells were pretreated with zVAD-fmk (Figure 4B). We also studied the effects of $z V A D$-fmk on $\Delta \psi \mathrm{m}$ decrease after 15 minutes of rPVL treatment. zVAD-fmk did not inhibit the rPVL-induced decrease in $\Delta \psi \mathrm{m}$, demonstrating that caspases are not involved upstream of mitochondria (Figure 4C).

PVL-induced PMN apoptosis preferentially activates caspases involved in the mitochondrial pathway. Caspases are synthesized as inactive zymogens and are activated by proteolytic cleavage, conveying the apoptotic signal in a proteolytic cascade. Caspase- 8 is the initial cas- pase triggered by death receptors, whereas caspase- 9 cleavage is the signature of the mitochondrial pathway. Caspase- 3 , an effector caspase, is activated by the initiator caspases- 8 and -9 . Protein extracts from untreated or rPVL-treated PMNs were prepared at various time points and subjected to SDS-PAGE followed by Western blotting with anti-caspase- $3,-8$, and -9 Abs. Freshly isolated PMNs or PMNs cultured during 6 hours without rPVL showed no caspase cleavage. After 30 minutes of treatment with $5 \mathrm{nM}$ rPVL, caspase- 9 was cleaved into its active form, p20, and caspase-3 was cleaved after 3 hours into its active form, p17. In contrast, caspase- 8 was never cleaved after rPVL treatment, whereas it was processed into its active form p18 in the positive control experiments (Figure 5A).

We took advantage of the different caspase inhibitors to determine the pathway involved during PVL-induced apoptosis. Caspase-8 inhibitor only partially decreased rPVL-induced apoptosis, whereas caspase-9 inhibitor was fully inhibitory (Figure 5B), sug- 
A
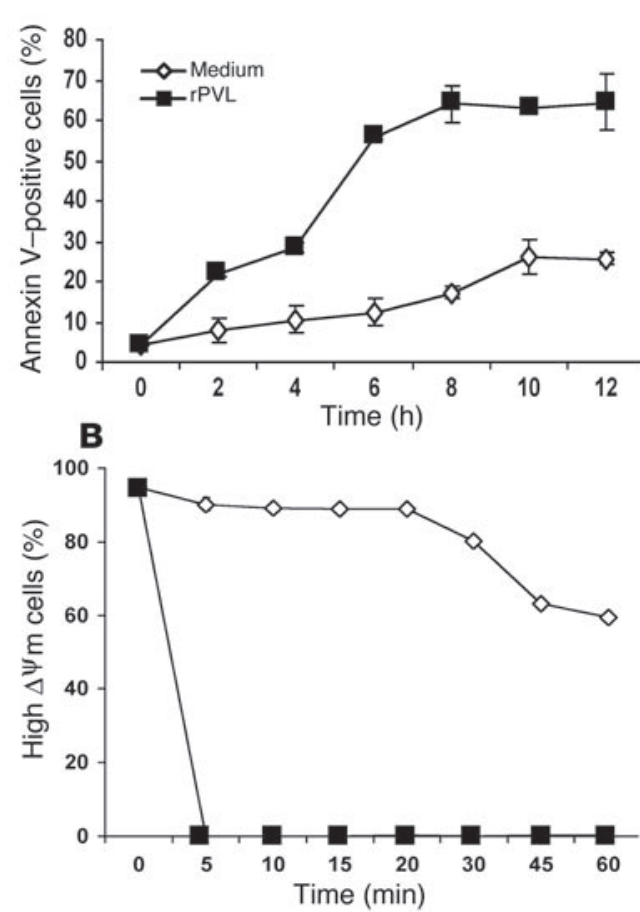

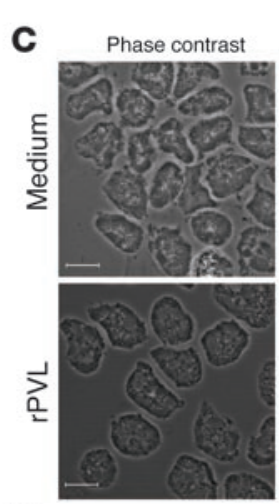

Phase contrast + immunofluorescence Immunofluorescence

D
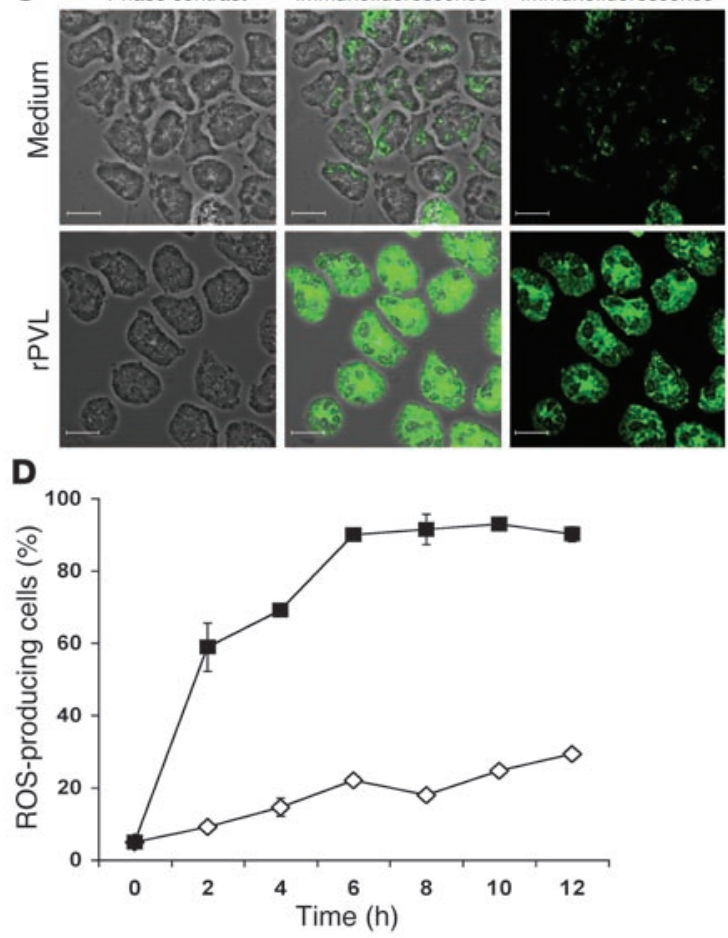

Figure 3

Kinetics of plasma membrane and mitochondrial alterations during rPVL-induced PMN apoptosis. PMNs were incubated with medium or with 5 $\mathrm{nM}$ rPVL and studied for annexin V binding (A), $\Delta \psi \mathrm{m}$ (B), mitochondrial membrane alterations (staining with MitoTracker GreenFM) (C), or ROS production (D). Results in $\mathbf{A}, \mathbf{B}$, and $\mathbf{D}$ are mean \pm SD of 3 data points. Data are from 1 of 3 independent experiments that gave similar results. (C) PMNs were observed using a laser scanning confocal microscope. Scale bars: $10 \mu \mathrm{m}$.

gesting that rPVL-induced PMN apoptosis preferentially uses caspases involved in the mitochondrial pathway.

Together our data suggest that the mitochondrial pathway is the major apoptotic pathway triggered by PVL in neutrophils.

The mitochondrion is a target of PVL. Since PVL is a pore-forming toxin, we wondered whether rPVL could directly target mitochondria and be responsible for their permeabilization. To this end, we first studied the localization of rPVL in PMNs. After 5 minutes of treatment, rPVL was only detected in permeabilized PMNs (Figure 6A), suggesting an intracellular localization of PVL. We then investigated the subcellular localization of PVL using protein extracts of subcellular fractions of PMNs treated with $5 \mathrm{nM} \mathrm{rPVL}$ for 5 or 30 minutes. As shown in Figure 6B, $\beta$-actin was found only in the cytoplasmic fraction, while manganese superoxidase dismutase (MnSOD) was only detected in the mitochondrial fraction, confirming the purity of the subcellular fractions. rLukS-PV was detected as early as 5 minutes in the mitochondrial fraction only (Figure 6B), suggesting that PVL directly targets mitochondria. In contrast, Bax, a proapoptotic member of the Bcl-2 family that relocates and oligomerizes in the outer membrane of mitochondria during apoptosis, leading to formation of pores (20), was only located in the cytoplasm of rPVL-treated PMNs even after 30 minutes (Figure 6B), indicating that rPVL-induced mitochondrial alterations are Bax independent. Furthermore, rPVLspecific gold labeling was associated with mitochondria on electron micrographs (Figure 6C), confirming the preferential PVL localization in the mitochondria.
PVL induces the release of Smac/DIABLO and cytochrome c from isolated mitochondria. We next determined whether PVL induces mitochondrial pores and the release of proapoptotic proteins from isolated mitochondria. As shown in Figure 7A, the incubation of isolated rat liver mitochondria with the 2 subunits of the rPVL toxins induced the release of the apoptogenic proteins cytochrome $c$ and Smac/DIABLO but not that of the control protein (i.e., subunit IV of the cytochrome $c$ oxidase) in a cell-free assay. Conversely, the addition of either rPVL subunit alone (only the effect of rLukS is illustrated in Figure 7B) had little or no effect on cytochrome $c$ and Smac/DIABLO release even at higher concentrations. As a control, we used purified recombinant Bax, and quite surprisingly, the efficacy of Bax in inducing cytochrome $c$ release was only 2 -fold higher than that of rPVL (Figure 7C), suggesting that both mitochondrial permeabilization actions occurred at similar rates. Of note, the quantity needed to induce the liberation of apoptogenic proteins from mitochondria is higher than that found in vitro to induce the decrease in $\Delta \psi \mathrm{m}$ (see Figure 3 ). This difference is likely to result from the experimental settings (in vitro versus cell-free experiments), and indeed, similar differences were also found with Bax itself (compare Figure 7 and the results obtained with the microinjection of recombinant Bax in vitro; ref. 21).

PVL production and apoptotic cell death in the lung during $S$. aureus necrotizing pneumonia. Approximately $90 \%$ of S. aureus necrotizing pneumonia are associated with isolation of $S$. aureus strains carrying PVL genes (1). To investigate whether PVL was secreted in the lung during necrotizing pneumonia, pulmonary necropsy sections 
A
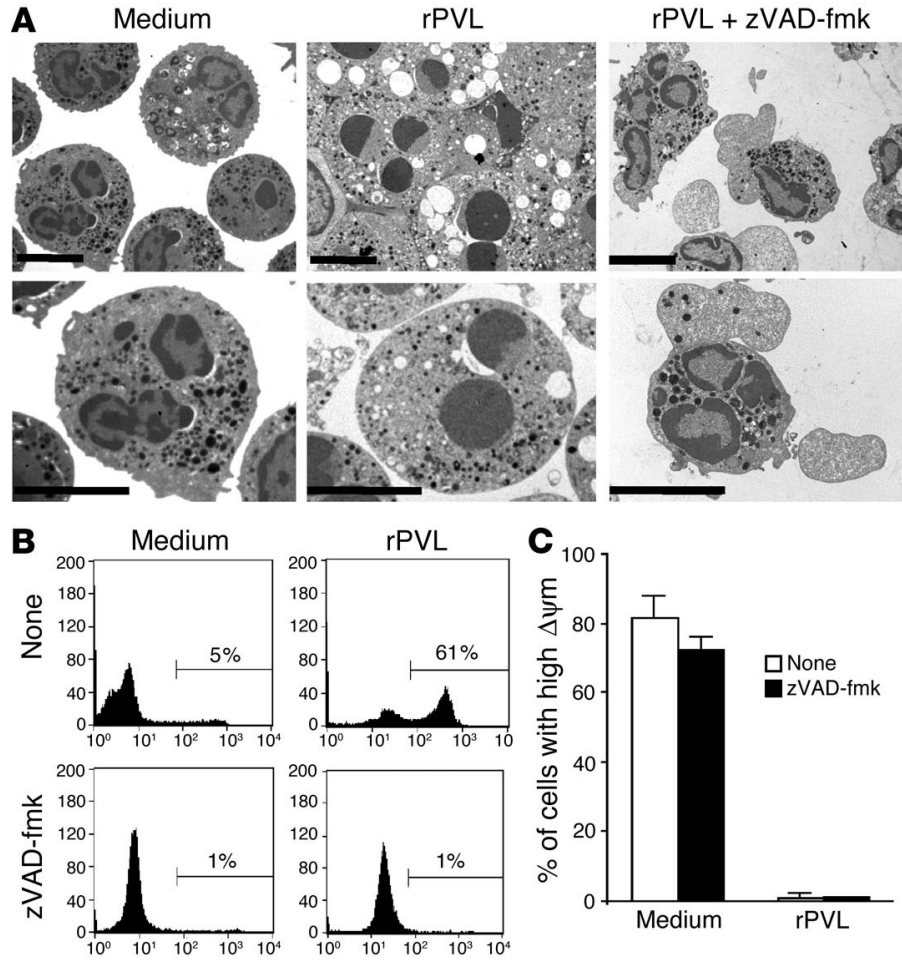

\section{Figure 4}

Effect of the caspase inhibitor zVAD-fmk on rPVL-induced PMN apoptosis. PMNs were incubated with zVAD-fmk $(100 \mu \mathrm{M})$ for 1 hour, then with medium or $5 \mathrm{nM} \mathrm{rPVL}$. (A) PMN morphology was observed after 6 hours using TEM. Scale bars: $20 \mu \mathrm{m}$. (B) DNA fragmentation was analyzed at 6 hours using the F7-26 mAb; the number indicated for each histogram represents the percentage of cells with fragmented DNA. (C) The $\Delta \psi \mathrm{m}$ decrease after zVAD-fmk treatment was observed after 15 minutes of PMN exposure to medium or $5 \mathrm{nM} \mathrm{rPVL}$. Results are mean \pm SD of 3 data points. Data are from 1 of 3 independent experiments that gave similar results.

often require a prolonged and aggressive antibiotic treatment. Among the most serious complications of $S$. aureus infections are manifestations of septic and toxic shock syndromes that may lead to multiple organ failure (25). We recently described a novel clinical entity, $S$. aureus necrotizing pneumonia, which is associated with a massive cell lysis of host pulmonary tissue and is highly lethal in young immunocompetent patients (1). We also found that these cases were strongly associated with $S$. aureus strains producing the otherwise very infrequent exotoxin PVL (1). In the present report, we demonstrated that PVL is a remarkable bacterial virulence factor because this toxin is localized in the pulmonary lesions of patients who died from necrotizing pneumonia and induces PMN apoptosis by directly targeting mitochondria.

Staphylococcal infections are typically associated with tiswere stained with anti-LukS 1C12 mAb. LukS-PV was detected in the different cell types such as endothelial cells and PMNs (Figure $8 \mathrm{~A}$ ), suggesting that PVL could be responsible for pulmonary lesions. Since PVL induces PMN apoptosis in vitro, we therefore wondered whether apoptosis could be involved in vivo during the course of necrotizing pneumonia. DNA fragmentation was detected by TUNEL in different cell types of serial pulmonary necropsy sections (Figure $8 \mathrm{~B}$ ), suggesting that $S$. aureus necrotizing pneumonia is associated with apoptotic cell death in the lung.

\section{Discussion}

S. aureus is one of the most common Gram-positive bacterial pathogens in humans. It is an opportunistic pathogen that colonizes the skin of approximately $20 \%$ of the population without causing clinical symptoms $(22,23)$. However, breached mucocutaneous membranes or impaired host immunity facilitate tissue invasion and bloodstream dissemination of S. aureus (24). This bacterium can cause serious infections often associated with abscess formation such as osteomyelitis, endocarditis, and pneumonia that

\section{Figure 5}

rPVL-induced PMN apoptosis uses caspases involved in the mitochondrial pathway. (A) Three-day-activated PBLs were incubated with medium or $5 \mu \mathrm{M}$ STS for 6 hours and PMNs were incubated with medium or with $5 \mathrm{nM}$ rPVL, and, at the indicated times, total protein extracts were prepared and proteins were separated on 12\% SDS-PAGE followed by Western blotting with anti-caspase-3, -8 or -9 Ab. Data are from 1 of 2 independent experiments that gave similar results. The cross represents a nonspecific band. (B) PMNs were incubated with medium or with $5 \mathrm{nM} \mathrm{rPVL}$ in the presence or absence of ZVAD-fmk $(100 \mu \mathrm{M})$, zIETD-fmk (100 $\mu \mathrm{M})$, or zLEHD-fmk $(100 \mu \mathrm{M})$. Apoptosis was measured as surface binding of annexin $V$. Results are mean \pm SD of 3 data points. Data are from 1 of 3 independent experiments that gave similar results. ${ }^{\star} P \leq 0.01 ;{ }^{\star \star} P \leq 0.001$. sue death. Induction of apoptosis by $S$. aureus may cause tissue damage, compromise the antimicrobial immune response, and thereby facilitate bacterial spread. $S$. aureus can induce apoptosis of epithelial cells (26-28), endothelial cells (29-31), keratinocytes (32), osteoblasts (33), lymphocytes, and macrophages (34).

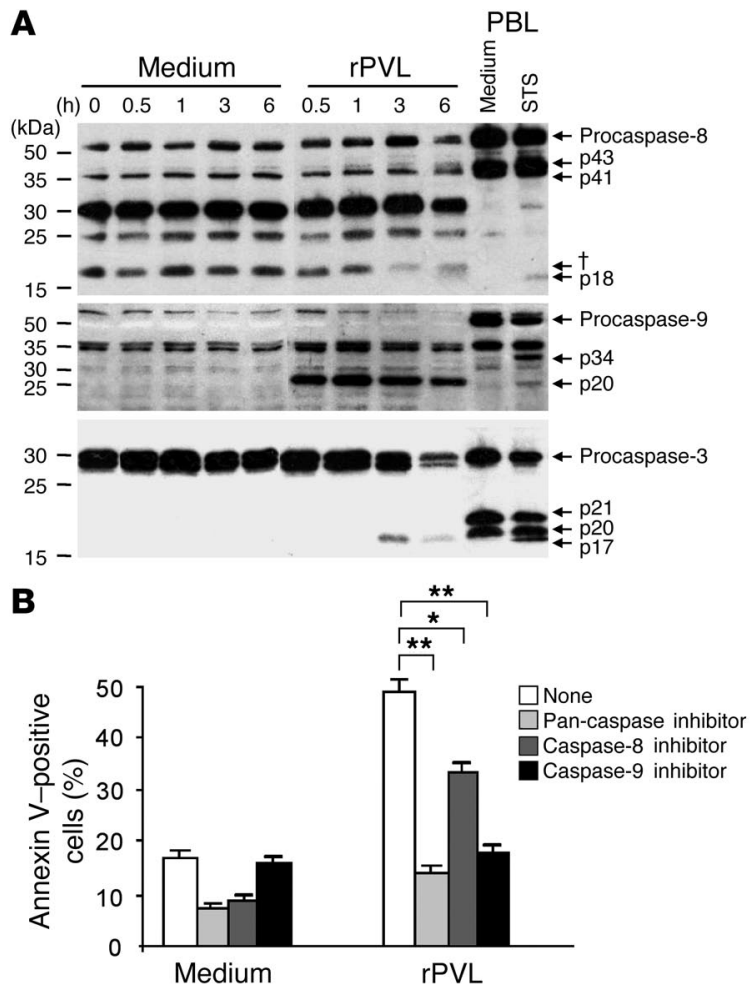


A
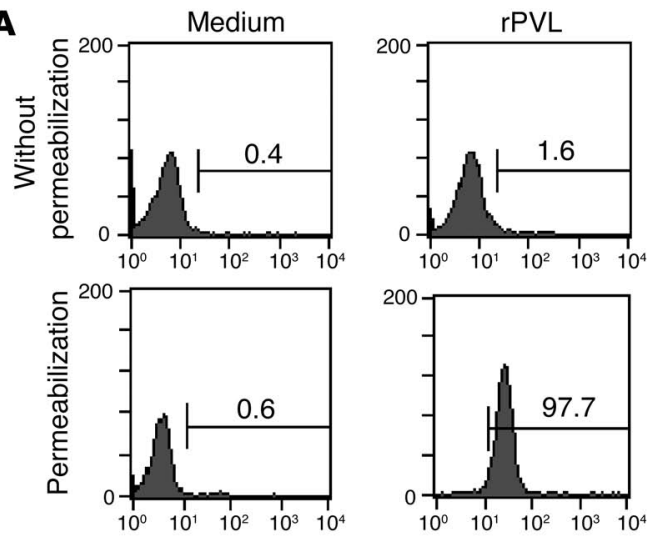

B

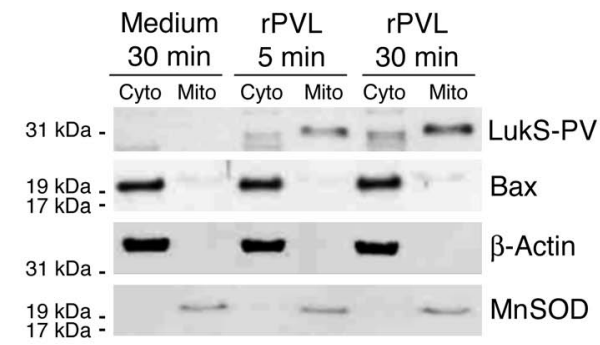

C

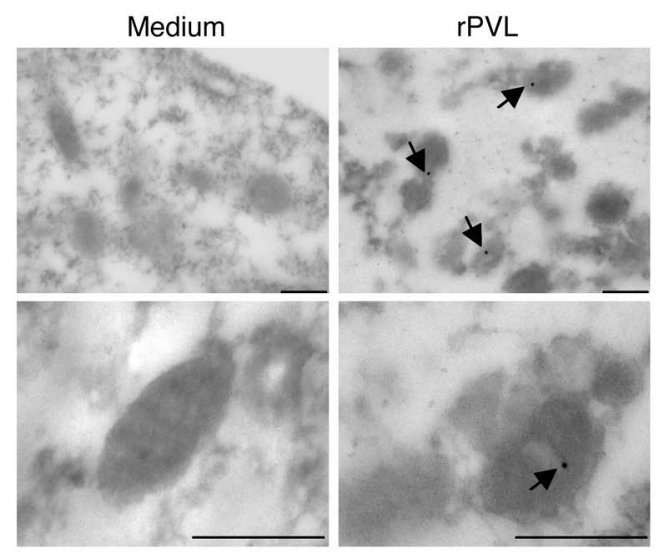

In epithelial cells, keratinocytes, or osteoblasts, S. aureus-induced apoptosis may require internalization of the bacteria $(26,27,30$, $32,33)$. Conversely, Bantel et al. (16) showed that S. aureus $\alpha$-toxin does not require bacterial internalization to induce apoptosis. Similarly, our data indicate that bacterial invasion of PMNs is not required for PVL to induce apoptosis. Hence, soluble PVL can be regarded as a mediator of $S$. aureus-induced neutrophil apoptosis, depleting neutrophils available for phagocytosis. Neutrophils transit through the human circulation en route to tissues, where they form the first line of cellular defense against invading bacterial pathogens. Phagocytosis of complement-opsonized targets is a primary function of neutrophils at sites of inflammation, and clearance, by apoptosis, of PMNs that have phagocytosed microbes is important for the resolution of inflammation (35). By inhibiting neutrophil phagocytosis, PVL could enhance the pathogenicity of

\section{Figure 6}

rPVL is localized in mitochondria during rPVL-induced PMN apoptosis. (A) PMNs were treated for 5 minutes with or without $5 \mathrm{nM}$ biotinylated $\mathrm{PPVL}$ and were then stained with streptavidin-FITC before (without permeabilization) or after (permeabilization) treatment with Cytofix/Cytoperm. (B) PMNs were incubated with medium or with 5 nM PVL and, at the indicated times, cytosolic and mitochondrial protein extracts were prepared and proteins were separated on $12 \%$ SDSPAGE followed by Western blotting with anti-MnSOD, anti- $\beta$-actin, anti-LukS-PV, or anti-Bax Ab. Anti-MnSOD Ab served as a marker of mitochondrial contamination of the cytosolic fractions (Cyto), while anti- $\beta$-actin $A b$ served as a marker of cytosolic contamination of mitochondrial fractions (Mito). Data are from 1 of 2 independent experiments that gave similar results. (C) PMNs were treated for 5 minutes with or without $5 \mathrm{nM}$ biotinylated $\mathrm{PPVL}$, prepared for TEM, and stained with gold-conjugated streptavidin. Arrows indicate gold-positive cells. Scale bars: $500 \mathrm{~nm}$.

S. aureus. Neutropenia is significantly more frequent in patients with necrotizing pneumonia caused by PVL-positive S. aureus than in patients with pneumonia caused by PVL-negative S. aureus (1) and could be due to the presence of PVL in pulmonary endothelial cells. Circulating PMNs could encounter PVL during their passage into the pulmonary vessels and therefore enter the cascade that leads to their apoptosis. As the cellular systems used in this study may not accurately reflect host-pathogen interactions in vivo, we cannot exclude the possibility that other staphylococcal exoproteins might contribute to human cell death.

Apoptosis was only triggered at low PVL concentrations, whereas higher concentrations induced necrotic alterations. These different actions may be related to the molecular properties of PVL. At low concentrations, PVL, which binds to specific but unidentified cell surface receptors (17), could produce small numbers of octameric pores (9). These pores could favor the entry of other PVL molecules into the cell, allowing the toxin to act on mitochondria and induce apoptosis. However, at high concentrations (200 nM), PVL may nonspecifically adsorb to the lipid bilayer, forming larger pores that are $\mathrm{Ca}^{2+}$ permissive, forming more numerous octameric pores, or leading to $\mathrm{Ca}^{2+}$ channel opening (36), all of which can result in necrosis. Moreover, larger pores would also lead to a loss of ATP, which is required for most apoptotic processes $(37,38)$. Thus, the modes of cell death in vivo (necrosis versus apoptosis) may critically depend of the PVL concentration. In staphylococcal infection, cells of the host tissue surrounding the bacteria are likely to be exposed to a PVL concentration gradient: necrosis would occur locally, while apoptosis would occur in the periphery and even in circulating blood cells. We confirmed on histological sections of lungs from patients who died of necrotizing pneumonia that apoptosis indeed

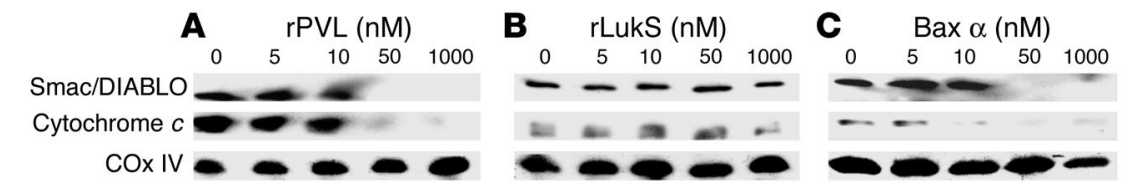

Figure 7

rPVL induces the release of the apoptogenic proteins cytochrome $c$ and Smac/DIABLO from isolated mitochondria. Mitochondria from rat liver were treated with increasing concentrations of $\mathrm{rPVL}(\mathbf{A})$, rLukS $(\mathbf{B})$, or Bax $\alpha(\mathbf{C})$ for 1 hour at $30^{\circ} \mathrm{C}$. Mitochondrial proteins were then separated by SDS-PAGE and analyzed by Western blotting using antibodies directed against cytochrome $c$, Smac/DIABLO, and cytochrome oxydase subunit IV (COx IV). Data are from 1 of 2 independent experiments that gave similar results. 
A

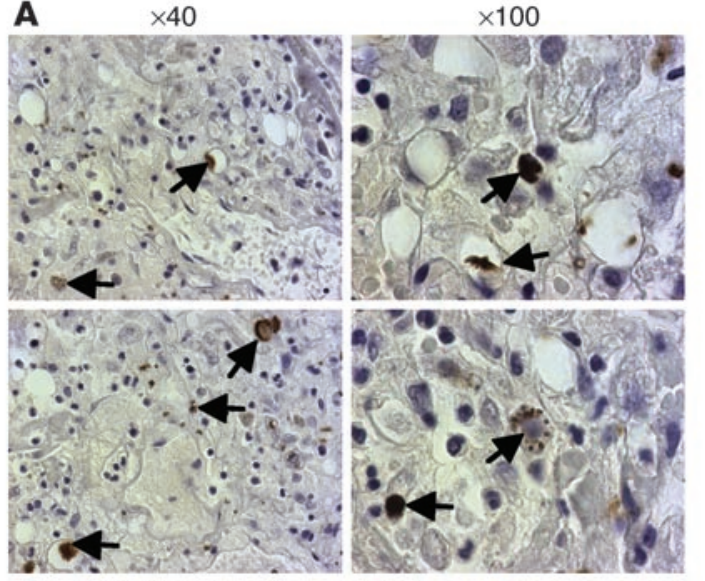

B
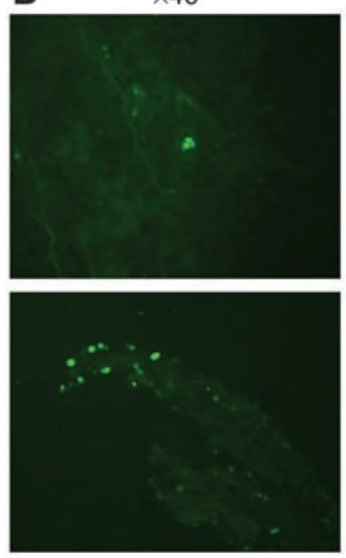

Figure 8

Detection of LukS-PV and of DNA-fragmented cells in lung sections of patients who died from necrotizing pneumonia. (A) Sections were stained with anti-LukS-PV 1C12 mAb. Arrows indicate LukS-PV-positive cells. (B) Serial sections were stained by the TUNEL method to detect DNA fragmentation.

occurs in vivo (Figure 8B), but further investigations will be needed to confirm the dual, concentration-dependent model of cell death as well as the PVL concentration achieved in vivo. In fulminant liver failure, tissue damage was first described as necrotic lesions. However, Strand et al. showed that these liver lesions resulted in apoptosis mediated by CD95/CD178 interactions (19). Similarly, the first lung lesions described by Gillet et al. (1) in patients with necrotizing pneumonia also suggested necrotic damage. However, monocytes and macrophages, which are responsible for apoptotic cell phagocytosis in vivo, are also known to be sensitive to PVL (8). Thus monocytes and macrophages, in addition to PMNs, could be killed by PVL in vivo. This could induce a decrease in physiological apoptotic cell phagocytosis and therefore lead to secondary necrosis, as observed on histological lung sections.

Although the pan-caspase inhibitor zVAD-fmk abrogated PVLinduced apoptosis, it did not suppress mitochondrial alterations, indicating that caspase activation occurs downstream of mitochondria. Furthermore, a specific caspase-9 inhibitor abrogated PVL-induced PMN apoptosis, whereas caspase-8 inhibitor was only partially effective. Finally, PVL activated not only the effector caspase- 3 but also caspase- 9 , the initiator caspase of the mitochon- drial pathway. In contrast, it did not activate caspase-8, the initiator caspase of the death receptor pathway. Thus, in contrast to other bacteria, including Psendomonas aeruginosa (39), Helicobacter pylori (40), and even S. aureus $(28,41)$, which can trigger apoptosis via CD95, our data clearly indicate that the death receptor pathway is not required for PVL-induced apoptosis in PMNs.

An early event in the mitochondrial pathway is the proapoptotic translocation of mitochondrial cytochrome $c$ into the cytosol, which is induced by proapoptotic proteins of the Bcl-2 family, such as Bax (42-44). Primary human neutrophils contain barely detectable levels of cytochrome $c$ and other mitochondrial proteins, but the trace amount of cytochrome $c$ present in neutrophils is both necessary and sufficient for Apaf-1-dependent caspase activation (45). We did not therefore analyze cytochrome $c$ release as an indicator of mitochondrial alterations, but the diffuse staining of MitoTracker and the rapid $\Delta \psi \mathrm{m}$ disruption after PVL treatment suggest that cytochrome $c$ is probably released during PVL-induced apoptosis. Indeed, addition of rPVL to isolated rat liver mitochondria induced the release of cytochrome $c$ and Smac/DIABLO, demonstrating the rapid mitochondrial alterations triggered by PVL.

Other bacterial proteins have been shown to induce apoptosis via the mitochondrial pathway. Indeed, $\mathrm{VacA}$, the vacuolating cytotoxin of H. pylori, has been shown to translocate to mitochondria and to induce mitochondrial cytochrome $c$ depletion (46). The Neisseria gonorrhoeae porin PorB has also been described to translocate to mitochondria and to induce cytochrome $c$ release (47). The S. aureus $\alpha$-toxin, which also induces cytochrome $c$ release, does not directly translocate to mitochondria in intact cells $(16,47)$. Although apoptosis induced by VacA, PorB, or $\alpha$-toxin has been reported to be inhibited by Bcl-2, the involvement of proapoptotic members of the Bcl-2 family, such as Bax, has not been studied $(16,46,47)$. In contrast to these reports, we clearly demonstrate that PVL does not require the proapoptotic protein Bax for its pore-forming action on mitochondria. However, it remains to be determined whether Bcl-2 could also inhibit the pore-forming activity of PVL.

Members of the Bcl-2 family (which as monomers do not induce pore formation) exhibit structural homology with colicins, poreforming toxins produced by E. coli (48). Furthermore, porins that form integral diffusion channels in the outer membrane of Gramnegative bacteria (49) exhibit structural and, in the case of the Neisseria porin (50), also functional homologies to eukaryotic porins. However, homology between members of the Bcl-2 family and exotoxin of Gram-positive bacteria such as $\alpha$-toxin or PVL secreted by S. aureus has not been described. However, our data demonstrating the release of cytochrome $c$ and Smac/DIABLO from isolated mitochondria are consistent with the possibility that PVL could localize to the outer mitochondrial membrane and trigger cytochrome $c$ release by pore formation independently of Bax. Whether PVL directly induces pores or interacts with mitochondrial membraneassociated protein to induce cytochrome $c$ release is still unknown and is a subject deserving of further study.

Three-quarters of patients with necrotizing pneumonia die despite appropriate antibiotic therapy, and alternative treatments are urgently needed. We have already proposed human polyclonal immunoglobulin (Tégélin) as a potential candidate for necrotizing pneumonia treatment. Indeed Tégélin contains anti-PVL antibodies and inhibits PVL-induced PMN necrosis in vitro (51). Caspase inhibitors have already shown their efficiency in treatment of experimental infections such as murine bacterial meningitis and 
sepsis (52-54). Our data suggest that caspase inhibitors might be beneficial in this setting and provide a rationale for studying their potential benefit in the treatment of necrotizing pneumonia. Taken together, our findings reveal promising insights into how $S$. aureus mediates cytotoxicity and provide a fundamental rationale for future therapeutic intervention in bacterial infections.

\section{Methods}

\section{Patient samples}

Lung necropsy specimens were taken from patients who died of necrotizing pneumonia, under conditions compliant with French biomedical legislation and approved by INSERM.

\section{Cell preparation and culture}

PMNs and peripheral blood lymphocytes (PBLs) were collected from healthy donors with their informed consent and with ethics committee approval (Etablissement Français du Sang). PBLs were prepared after blood defibrination, then mononuclear cells were isolated by centrifugation on a layer of Histopaque (Eurobio). PMNs were isolated by dextran sedimentation and centrifugation using Polymorphprep (AXIS-SHIELD PoC AS). Briefly, $20 \mathrm{ml}$ of sodium citrate-anticoagulated whole blood was carefully layered over $20 \mathrm{ml}$ of Polymorphprep in a 50-ml centrifuge tube. Mononuclear cells and platelets were removed by density gradient centrifugation. When necessary, erythrocytes were lysed by short treatment of the pellet with an ice-cold isotonic $\mathrm{NH}_{4} \mathrm{Cl}$ solution $\left(155 \mathrm{mM} \mathrm{NH}_{4} \mathrm{Cl}, 10\right.$ $\mathrm{mM} \mathrm{KHCO}_{3}, 0.1 \mathrm{mM}$ EDTA, pH 7.4). PMNs were washed twice in HBSS and used for further manipulations. Viable PMNs were determined by the trypan blue exclusion method. The percentage of viable cells ranged from $97 \%$ to $99 \%$. In all cases, cell purity was above $97 \%$ as observed after May-Grünwald and Giemsa staining. Fresh PMNs were prepared for each day's experiments, as viability fell after 8 hours. PMNs and PBLs were resuspended at a final density of $0.5 \times 10^{6}$ to $1 \times 10^{6} / \mathrm{ml}$ in RPMI 1640 culture medium (Gibco-BRL; Invitrogen Corp.) supplemented with $10 \%$ heat-inactivated FCS (Gibco-BRL; Invitrogen Corp.), $100 \mathrm{U} / \mathrm{ml}$ penicillin, $100 \mu \mathrm{g} / \mathrm{ml}$ streptomycin, and $2 \mathrm{mM} \mathrm{L}$-glutamine. All incubations were performed at $37^{\circ} \mathrm{C}$ in humidified air with $5 \% \mathrm{CO}_{2}$.

\section{Production of isogenic strains}

The Staphylococcus aureus strain RN6390 (luk-PV -) was lysogenized using 50 $\mu l$ of $\Phi$ SLT phage carrying $l u k-P V\left(10^{11}-10^{12} \mathrm{PFU} / \mathrm{ml}\right)$. The inactivation of the PVL gene (lukS-PV and $l u k F-P V)$ was then carried out by allelic replacement. A deletion/replacement $\Delta l u k$-PV:tet $M$ mutant of S. aureus RN6390 ФSLT was obtained using PMAD, a thermo-sensitive plasmid that contains a constitutively expressed $\beta$-galactosidase gene, thus allowing positive selection of double crossover by following the $\beta$-galactosidase activity on X-gal agar plates (55). A 2.9-kbp DNA fragment corresponding to the tetracycline resistance gene tet $M$ (55) was cloned between 2 DNA fragments generated using oligonucleotides phi262 (TATCTAGAATAGTCCACAACGTCG)/phi869 (ACGGATCCAGCGCCATCACC) (607 bp) and phi2277 (ATGAATTCGGGACCATATGGC)/phi2817 (TAATCGATCCACAAGTGTTTGCC) (540 bp), corresponding, respectively, to the chromosomal DNA regions upstream of lukS (encompassing the first 39 codons) and downstream of $l u k F$ (from codon 200 to the end), in pMAD (56). The resulting plasmid, pLUG505, was electroporated into RN4220 and then into RN6390 ФSLT. Transformants were grown at the nonpermissive temperature $\left(37^{\circ} \mathrm{C}\right)$ to select for cells in which the plasmid had been integrated into the chromosome by homologous recombination. To favor the second recombination event, a single colony was grown at $30^{\circ} \mathrm{C}$ for 10 generations and plated at $37^{\circ} \mathrm{C}$ overnight. Cells, which had lost the plasmid vec- tor through a double-crossover event, were detected on X-gal agar plates. PCR amplifications were used to confirm the replacement of most of the $l u k-P V$ genes (codon 38 of $l u k S$ to 199 of $l u k F$ ) by the tet $M$ gene.

\section{Production of native LukS-PV and LukF-PV proteins}

LukS-PV and LukF-PV proteins were prepared as described previously $(5,57)$.

\section{Production, purification, and biotinylation of $r L u k S-P V$ and rLukF-PV proteins}

The pIVEX2.4d vector (Roche Diagnostics Corp.) was used to produce recombinant 6 His-tagged LukS-PV and LukF-PV proteins (the 2 components of PVL). Primers were designed following identification of suitable hybridization sites in the $l u k S-P V$ and $l u k F-P V$ genes. The $5^{\prime}$ primers (rLukS-1: 5'-ACCCTTAATTAAAGAATCTAAAGCTGATAACAATATTGAGAATATTG-3'; and rLukF-1: 5'-ACCCTTAATTAAAGCTCAACATATCACACCTGTAAG-3') were chosen within the coding sequence of each gene (GenBank accession number X72700), omitting the region predicted to encode the signal peptide as published and verified by hydrophobicity analysis according to Kyte and Doolittle (58) and the SignalP version 1.1 World Wide Web Prediction Server (http://www.cbs.dtu.dk/ services/SignalP/). The 3' primers (rLukS-2: 5'-ACGCGGATCCTCAATTATGTCCTTTCACTTTAATTTCATGAG-3'; and rLukF-2: 5'-ACGCGGATCCTTAGCTCATAGGATTTTTTTCCTTAGATTG-3') were chosen to encompass the stop codon of each gene. Restriction sites (PacI for rLukS-1 and rLukF-1; BamH1 for rLukS-2 and rLukF-2) were included in each primer. DNA was extracted from S. aureus reference strain ATCC 49775 and used as a template for PCR amplification. PCR products and plasmid DNA were prepared using the QIAGEN plasmid kit. PCR fragments were digested with PacI (Ozyme) and BamH1 (Promega) and ligated using T4 DNA ligase (Promega), with the pIVEX2.4d expression vector digested with the same restriction enzymes. The resulting plasmids were transformed into E. coli DH5 $\alpha$ (Stratagene) before transformation into E. coli BL21star(DE3)pLys (Invitrogen Corp.) for gene expression. The integrity of the open reading frame of each construct was verified by DNA sequencing. The fusion proteins (6His-LukS-PV and 6His-LukF-PV) were purified from lysates of transfected $E$. coli cells by affinity chromatography on nitrilotriacetic acid columns according to the manufacturer's instructions (QIAGEN). The purity of the fusion proteins was controlled by 7.5\% SDSPAGE. The fusion proteins, $6 \mathrm{His}-\mathrm{LukS}-\mathrm{PV}$ and $6 \mathrm{His}-\mathrm{LukF}-\mathrm{PV}$, were then lyophilized and stored at $4^{\circ} \mathrm{C}$ until use. When necessary, 6His-LukS-PV and 6 His-LukF-PV were biotinylated using the BiotinTag Micro Biotinylation Kit (Sigma-Aldrich) following the manufacturer's instructions. As PVL is a 2-component toxin, whenever using PVL, equimolar concentrations of 6His-LukS-PV and 6His-LukF-PV were used.

\section{Generation of anti-LukS-PV mAbs}

Six-week-old female BALB/c mice were immunized by intraperitoneal injection of LukS-PV $(25 \mu \mathrm{g}) 4$ times at 14-day intervals. Splenocytes were fused with NSI 9046 mouse myeloma cells 3 days after the final injection as previously described (59). After hypoxanthine-aminopterin-thymidine selection, the mAbs were screened by ELISA. The mAb 1C12 was identified by ELISA and cloned by limiting dilution (Agro-Bio). Pure culture supernatants were used for necropsy section staining using the EnVision kit according to the manufacturer's instructions (DakoCytomation).

\section{Measurement of cell death}

Morphologic studies of PMNs. PMNs $\left(3 \times 10^{5}\right)$ were cytospun and examined for morphologic changes after staining with May-Grünwald/Giemsa solution or $10 \mu \mathrm{g} / \mathrm{ml} \mathrm{Hoechst} 33342$ (Sigma-Aldrich), using an epifluorescence Zeiss microscope. 
Evaluation of alterations in cell membrane asymmetry. Phosphatidylserine exposure was quantified by surface binding of annexin $V(60)$. Briefly, $2 \times 10^{5}$ cells were resuspended in annexin $\mathrm{V}$ binding buffer containing FITC-conjugated annexin $\mathrm{V}$ for 15 minutes following the manufacturer's instructions (Bender MedSystems). In order to determine alterations in cellular membrane integrity, propidium iodide was then added at a final concentration of $1 \mu \mathrm{g} / \mathrm{ml}$, and the cell suspension was immediately analyzed by flow cytometry using a FACScalibur flow cytometer and CellQuest Pro software (version 4.0.2; BD Biosciences). Annexin V-FITC-positive cells were assumed to be apoptotic.

DNA fragmentation assays. Single-stranded DNA fragmentation was detected using Apostain F7-26 mAb from Alexis Corp., according to the manufacturer's instructions.

DNA fragmentation in histological sections was detected by the TUNEL method implemented with the In Situ Cell Death Detection Kit (Boehringer Mannheim). The labeling reaction was carried out by adding terminal deoxynucleotidyl transferase, dUTP-FITC, and unlabeled nucleotides and incubating the slides at $37^{\circ} \mathrm{C}$ for 1 hour. The histopathological sections were then visualized by fluorescence microscopy.

Measurement of $\Delta \psi m . \Delta \psi \mathrm{m}$ was determined by incubating PMNs at $37^{\circ} \mathrm{C}$ for 30 minutes with $40 \mathrm{nM}$ cationic fluorochrome 3,3'-dihexylocarbocyanine iodide [DiOC 6 (3); Molecular Probes, Invitrogen Corp.] in PBS (61), followed by immediate analysis with a FACScalibur flow cytometer and CellQuest software (BD Biosciences).

ROS detection. ROS production was assessed by incubating PMNs at $37^{\circ} \mathrm{C}$ for 15 minutes with $2 \mu \mathrm{M}$ hydroxyethidium (Molecular Probes; Invitrogen Corp.), followed by immediate analysis with a FACScalibur flow cytometer and CellQuest software (BD Biosciences).

Caspase inhibitors. The broad-spectrum caspase inhibitor zVAD-fmk was purchased from Bachem. Inhibitors of caspase-8 [CBz-Ile-Glu-ThrAsp(OMe)-fluoromethylketone] (zIETD-fmk) and caspase-9 [CBz-Leu-GluHis-Asp(OMe)-fluoromethylketone] (zLEHD-fmk) were from Calbiochem.

\section{Western blotting}

Caspase-9, -8 , and -3 cleavage was examined by Western blotting. Activated T lymphocytes were obtained by activation of PBLs for 3 days with $5 \mu \mathrm{g} / \mathrm{ml}$ of phytohemagglutinin (Sigma-Aldrich). At this stage dead cells were removed, and viable cells $\left(10^{6} / \mathrm{ml}\right)$ were treated with $5 \mu \mathrm{M}$ staurosporine (Sigma-Aldrich) for 6 hours. Briefly, $10^{7}$ PMNs incubated with medium or with $5 \mathrm{nM}$ PVL for indicated times or treated PBLs were washed in PBS and resuspended in $100 \mu \mathrm{l}$ of lysis buffer $(10 \mathrm{mM}$ Tris- $\mathrm{HCl} \mathrm{pH}$ 7.6, $150 \mathrm{mM}$ $\mathrm{NaCl}, 10 \mathrm{mM}$ EDTA, 1\% Triton X-100, $1 \mathrm{mM}$ PMSF, $10 \mu \mathrm{g} / \mathrm{ml}$ leupeptin, $10 \mu \mathrm{g} / \mathrm{ml}$ aprotinin). After incubation for 10 minutes on ice, the lysates were centrifuged for 15 minutes at $10,000 \mathrm{~g}$ at $4{ }^{\circ} \mathrm{C}$, and the protein extracts were frozen. The protein concentration of each extract was determined using the BC Assay kit (Uptima Interchim). Thirty micrograms of protein extract was resolved by $12 \%$ SDS-PAGE and electrotransferred to nitrocellulose membranes (Schleicher \& Schuell BioScience Inc.). The blots were probed with a mouse anti-human caspase- $8 \mathrm{mAb}$ (kindly provided by P. H. Krammer, German Cancer Research Center, Heidelberg, Germany), with rabbit polyclonal anti-human caspase-9 (New England Biolabs Inc.), or with rabbit polyclonal anti-human caspase-3 (BD Biosciences - Pharmingen). Bound primary Ab was detected by adding an appropriate secondary Ab conjugated to HRP (Amersham Biosciences Europe). An enhanced chemiluminescence system (ECL; Amersham Biosciences Europe) was used for detection.

For subcellular fractions, cytosol and mitochondria-enriched PMN fractions were generated with a digitonin-based subcellular fractionation technique, essentially as previously described $(45,62)$. In brief, $5 \times 10^{7}$ cells were harvested by centrifugation at $800 \mathrm{~g}$, washed in PBS pH 7.2, and centrifuged. PMNs were permeabilized for 5 minutes on ice at a density of $5 \times 10^{7} / \mathrm{ml}$ in cytosolic extraction buffer ( $250 \mathrm{mM}$ sucrose, $70 \mathrm{mM} \mathrm{KCl}, 137 \mathrm{mM} \mathrm{NaCl}, 4.3$ $\mathrm{mM} \mathrm{Na}_{2} \mathrm{HPO}_{4}, 1.4 \mathrm{mM} \mathrm{KH}_{2} \mathrm{PO}_{4}$, pH 7.2, $100 \mu \mathrm{M}$ PMSF, $10 \mu \mathrm{g} / \mathrm{ml}$ leupeptin, $2 \mu \mathrm{g} / \mathrm{ml}$ aprotinin, and $25 \mu \mathrm{g} / \mathrm{ml}$ digitonin). Plasma membrane permeabilization was confirmed by staining with $0.2 \%$ trypan blue solution. Cells were centrifuged at $10,000 \mathrm{~g}$ for 10 minutes at $4^{\circ} \mathrm{C}$, the supernatants (cytosolic fractions) were saved, and the pellets were solubilized in the same volume of mitochondrial lysis buffer (50 mM Tris, pH 7.4, $150 \mathrm{mM} \mathrm{NaCl}, 2$ mM EDTA, 2 mM EGTA, 0.2\% Triton X-100, 0.3\% NP-40, $100 \mu \mathrm{M}$ PMSF, $10 \mu \mathrm{g} / \mathrm{ml} \mathrm{leu-}$ peptin, $2 \mu \mathrm{g} / \mathrm{ml}$ aprotinin) and incubated for 20 minutes on ice. The mitochondria-enriched fractions were then centrifuged at $10,000 \mathrm{~g}$ for 10 minutes at $4{ }^{\circ} \mathrm{C}$, and the supernatant from high-speed centrifugation was used as the mitochondrial fraction. For the detection of $\beta$-actin, MnSOD, LukS-PV, and $\mathrm{Bax}, 50 \mu \mathrm{g}$ of protein extracts were resolved on $12 \%$ SDS-PAGE and electrotransferred to nitrocellulose membranes (Schleicher \& Schuell BioScience Inc.). The blots were probed with mouse anti-human $\beta$-actin mAb (BD Biosciences - Pharmingen), with rabbit polyclonal anti-human MnSOD Ab (StressGen Biotechnologies), with rabbit polyclonal anti-LukS-PV Ab (Agro-Bio), or with rabbit polyclonal anti-Bax $\mathrm{Ab}$ (BD Biosciences - Pharmingen).

\section{Mitochondrial cell-free assay}

Mitochondria were prepared from normal rat liver. The cell-free assay was performed using $100 \mu \mathrm{g}$ mitochondrial proteins in $40 \mu \mathrm{l}$ standard import buffer $\left(250 \mathrm{mM}\right.$ sucrose, $80 \mathrm{mM} \mathrm{KCl}, 10 \mathrm{mM} \mathrm{MgCl}_{2}, 10 \mathrm{mM}$ malic acid, $8 \mathrm{mM}$ succinic acid, $1 \mathrm{mM}$ ATP-Mg2+, $20 \mathrm{mM}$ Mops, $\mathrm{pH}$ 7.5) containing PVL-toxin (equimolar quantities of LukS and LukF subunits), LukS subunit, or Bax $\alpha$. The concentrations used were $0,5,10,50$, and 1,000 nM. Mitochondria were incubated for 1 hour at $30^{\circ} \mathrm{C}$. After centrifugation for 10 minutes at $4^{\circ} \mathrm{C}$ at $8,000 \mathrm{~g}$, the mitochondrial proteins were separated by SDS-PAGE using a $15 \%$ acrylamide/bisacrylamide running gel and analyzed by Western blotting. Antibodies directed against cytochrome $c$ (dilution: 1:2,000; R\&D Systems), Smac/DIABLO (dilution: 1:1,000; ProSci. Inc.), and cytochrome oxydase subunit IV (dilution: 1:2,000; Molecular Probes, Invitrogen Corp.) were used for immunoblot analysis.

\section{TEM}

Cell morphology following PVL treatment was examined by TEM. Nuclear fragmentation and/or marked chromatin are typical features of apoptotic cells. Cells (toxin-treated and untreated) were fixed, dehydrated, embedded, cut, and observed. Briefly, cell suspensions were fixed for 30 minutes by adding to the medium an equal volume of $4 \%$ glutaraldehyde. The cells were then washed 3 times in $0.2 \mathrm{M} \mathrm{Na}$ cacodylate- $\mathrm{HCl} \mathrm{pH} 7.4$ for $10 \mathrm{~min}$ utes and post-fixed with $1 \% \mathrm{OsO}_{4} / 0.15 \mathrm{M} \mathrm{Na}$ cacodylate/ $\mathrm{HCl}, \mathrm{pH} 7.4$, for 30 minutes. The cells were dehydrated with an increasing ethanol gradient (5 minutes in $30 \%, 50 \%, 70 \%$, and $95 \%$ and 3 times for 10 minutes in pure ethanol). Impregnation was performed with Epon A (50\%) plus Epon B $(50 \%)$ plus DMP30 (1.7\%). Inclusion was obtained by polymerization of the Epon mixture $\left(60^{\circ} \mathrm{C}, 72\right.$ hours). Sections $60-80 \mathrm{~nm}$ thick were cut with an ultramicrotome (RMC MTX; Elexience), recovered on copper grids, and contrasted with uranyl acetate and lead citrate. Sections were examined and viewed with a JEOL 1200CX transmission electron microscope (Jeol).

PVL was located by gold staining and TEM. Cells (toxin-treated and untreated) were fixed, dehydrated, embedded, cut, stained, and observed. Briefly, PMN suspensions $\left(30 \times 10^{6}\right.$ cells) were treated in the presence or absence of $5 \mathrm{nM}$ biotinylated PVL ( $5 \mathrm{nM}$ biotinylated 6 His-LukS-PV and 5 $\mathrm{nM}$ biotinylated $6 \mathrm{His}-\mathrm{LukF}-\mathrm{PV})$. After 5 minutes, PMNs were centrifuged and fixed for 1 hour at $4{ }^{\circ} \mathrm{C}$ using $6 \mathrm{ml}$ of PLP (8\% paraformaldehyde 1:4, phosphate-lysine 3:4, glutaraldehyde). The cells were then washed 3 times in PLS buffer (phosphate, lysine, saccharose), and dehydrated with an increasing ethanol gradient ( 5 minutes in 30\%,50\%,70\%, and $95 \%$ and 3 times for 10 minutes in pure ethanol). Impregnation was performed with $\times 3$ London resin 
white. Inclusion was obtained by polymerization of the London resin white $\left(60^{\circ} \mathrm{C}, 72\right.$ hours). Sections $60-80 \mathrm{~nm}$ thick were cut with an ultramicrotome (RMC MTX; Elexience) and recovered on 200 mesh nickel grids. PMNs were then stained with gold-conjugated streptavidin (BBInternational) and contrasted with 5\% uranyl acetate in 50\% ethanol. Sections were examined and viewed with a JEOL 1200CX transmission electron microscope.

\section{Immunofluorescence and confocal laser scanning microscopy}

MitoTracker GreenFM (Molecular Probes; Invitrogen Corp.) was used for mitochondrial staining. Briefly, $3 \times 10^{5}$ PVL-treated or untreated PMNs were incubated for 30 minutes at $37^{\circ} \mathrm{C}$ with $5 \mu \mathrm{M}$ of MitoTracker GreenFM. PMNs were then seeded on glass coverslips by the cytospin method and fixed in 3.7\% paraformaldehyde for 10 minutes. Cells were observed under a laser scanning confocal microscope (LSM 510; Zeiss), and images were processed with Adobe Photoshop software (version 7.0; Adobe Systems Inc.).

\section{PVL location in PMNs by flow cytometry}

PMNs $\left(10^{6}\right)$ were incubated for 5 minutes with or without $5 \mathrm{nM}$ biotinylated PVL $(5 \mathrm{nM}$ biotinylated 6 His-LukS-PV plus $5 \mathrm{nM}$ biotinylated 6 HisLukF-PV). Cells were then stained for 30 minutes at $4^{\circ} \mathrm{C}$ with $100 \mu \mathrm{l}$ of FITC-conjugated streptavidin (BD Biosciences - Pharmingen) before or after permeabilization with Cytofix/Cytoperm (BD Biosciences - Pharmingen) following the manufacturer's instructions. After 3 washes with PBS/ BSA/azide, PMNs were analyzed with a FACScalibur flow cytometer and CellQuest software (BD Biosciences).

\section{Statistics}

Data are expressed as mean \pm SD. Statistical significance of differences was determined by the paired 2-tailed Student's $t$ test. Differences were considered statistically significant for $P$ values $\leq 0.01\left({ }^{*}\right)$ or $0.001\left({ }^{* *}\right)$.

\section{Acknowledgments}

This work was supported by the Action Concertée Incitative Microbiologie of the Ministère de la Recherche et des Nouvelles Technologies. We are grateful to G. Delorme, V. Chamouard, M. Bes, Y. Benito, C. Badiou, and F. Couzon for their technical assistance and to D. Young for editing the manuscript.

Received for publication July 12, 2004, and accepted in revised form August 23, 2005.

Address correspondence to: Laurent Genestier, INSERM U404, Tour CERVI, 21, avenue Tony Garnier, 69365 Lyon cedex 07, France. Phone: 33-4-37-28-24-55; Fax: 33-4-37-28-23-41; E-mail: genestier@cervi-lyon.inserm.fr. Or to: François Vandenesch, INSERM E0230, IFR62, Faculté de Médecine RTH Laennec, Rue Guillaume Paradin, 69372 Lyon cedex 08, France. Phone: 33-4-7877-86-57; Fax: 33-4-78-77-86-58; E-mail: denesch@univ-lyon1.fr.

Laurent Genestier and François Vandenesch contributed equally to this work.
1. Gillet, Y., et al. 2002. Association between Staphylococcus aureus strains carrying gene for PantonValentine leukocidin and highly lethal necrotising pneumonia in young immunocompetent patients. Lancet. 359:753-759.

2. Hunt, C., et al. 1999. Four pediatric deaths from community-acquired methicillin-resistant Staphylococcus aureus - Minnesota and North Dakota, 1997-1999. JAMA. 282:1123-1125.

3. Melles, D.C., et al. 2004. Natural population dynamics and expansion of pathogenic clones of Staphylococcus aureus. J. Clin. Invest. 114:1732-1740. doi:10.1172/JCI200423083.

4. Foster, T.J. 2004. The Staphylococcus aureus "superbug." J. Clin. Invest. 114:1693-1696. doi:10.1172/ JCI200423825.

5. Pédelacq, J.D., et al. 1999. The structure of a Staphylococcus aureus leucocidin component (LukF-PV) reveals the fold of the water-soluble species of a family of transmembrane pore-forming toxins. Structure Fold. Des. 7:277-287.

6. Prévost, G., et al. 1995. Panton-Valentine leucocidin and gamma-hemolysin from Staphylococcus aureus ATCC 49775 are encoded by distinct genetic loci and have different biological activities. Infect. Immun. 63:4121-4129.

7. Woodin, A.M. 1959. Fractionation of a leucocidin from Staphylococcus aureus. Biochem. J. 73:225-237.

8. Gladstone, G.P., and Van Heyningen, W.E. 1957. Staphylococcal leucocidins. Br. J. Exp. Pathol. 38:123-137.

9. Miles, G., Movileanu, L., and Bayley, H. 2002. Subunit composition of a bicomponent toxin: staphylococcal leukocidin forms an octameric transmembrane pore. Protein Sci. 11:894-902.

10. Colin, D.A., Mazurier, I., Sire, S., and Finck-Barbancon, V. 1994. Interaction of the two components of leukocidin from Staphylococcus aureus with human polymorphonuclear leukocyte membranes: sequential binding and subsequent activation. Infect. Immun. 62:3184-3188.

11. Finck-Barbancon, V., Duportail, G., Meunier, O., and Colin, D.A. 1993. Pore formation by a two-component leukocidin from Staphylococcus aureus within the membrane of human polymorphonuclear leukocytes. Biochim. Biophys. Acta. 1182:275-282.

12. Hensler, T., et al. 1994. Leukotriene B4 generation and DNA fragmentation induced by leukocidin from Staphylococcus aureus: protective role of granulocyte-macrophage colony-stimulating factor (GM-CSF) and G-CSF for human neutrophils. Infect. Immun. 62:2529-2535.

13. König, B., Prévost, G., Piémont, Y., and König, W 1995. Effects of Staphylococcus aureus leukocidins on inflammatory mediator release from human granulocytes. J. Infect. Dis. 171:607-613.

14. Meunier, O., Falkenrodt, A., Monteil, H., and Colin, D.A. 1995. Application of flow cytometry in toxinology: pathophysiology of human polymorphonuclear leukocytes damaged by a pore-forming toxin from Staphylococcus aureus. Cytometry. 21:241-247.

15. Kanoe, M., Yamamoto, T., Kai, K., and Blobel, H. 1988. Effects of leukocidin from Fusobacterium necrophorum on bovine peripheral leukocytes in vitro. Zentralbl. Bakteriol. Mikrobiol. Hyg. [A]. 268:463-469.

16. Bantel, H., et al. 2001. $\alpha$-Toxin is a mediator of Staphylococcus aureus-induced cell death and activates caspases via the intrinsic death pathway independently of death receptor signaling. J. Cell Biol. 155:637-648.

17. Gauduchon, V., Werner, S., Prevost, G., Monteil, H., and Colin, D.A. 2001. Flow cytometric determination of Panton-Valentine leucocidin S component binding. Infect. Immun. 69:2390-2395.

18. Morinaga, N., Nagamori, M., and Kato, I. 1988. Changes in binding of staphylococcal leukocidin to HL-60 cells during differentiation induced by dimethyl sulfoxide. Infect. Immun. 56:2479-2483.

19. Strand, S., et al. 1998. Hepatic failure and liver cell damage in acute Wilson's disease involve CD95 (APO-1/Fas) mediated apoptosis. Nat. Med. 4:588-593.

20. Antonsson, B., Montessuit, S., Lauper, S., Eskes, R., and Martinou, J.C. 2000. Bax oligomerization is required for channel-forming activity in liposomes and to trigger cytochrome $\mathrm{c}$ release from mitochondria. Biochem. J. 345:271-278.

21. Moreau, C., et al. 2003. Minimal BH3 peptides promote cell death by antagonizing anti-apoptotic proteins. J. Biol. Chem. 278:19426-19435.

22. Kissane, J.M. 1997. Staphylococcal infections. In Pathology of infectious diseases. D.H. Connor, F.W. Chandler, H.J. Schwartz, H.J. Manz, and E.E. Laak, editors. Appleton and Lange. Stamford, Connecticut, USA. 805-816.

23. Lowy, F.D. 1998. Staphylococcus aureus infections. N. Engl. J. Med. 339:520-532.

24. Rupp, M.E. 1997. Infections of intravascular catheters and vascular devices. In The staphylococci in buman disease. K.B. Crossley and G.L. Archer, editors. Churchill Livingstone. New York, New York, USA. 379-399.

25. Marrack, P., and Kappler, J. 1990. The staphylococcal enterotoxins and their relatives [erratum]. Science. 248:1066.

26. Bayles, K.W., et al. 1998. Intracellular Staphylococcus aureus escapes the endosome and induces apoptosis in epithelial cells. Infect. Immun. 66:336-342.

27. Kahl, B.C., et al. 2000. Staphylococcus aureus RN6390 replicates and induces apoptosis in a pulmonary epithelial cell line. Infect. Immun. 68:5385-5392.

28. Wesson, C.A., et al. 2000. Apoptosis induced by Staphylococcus aureus in epithelial cells utilizes a mechanism involving caspases 8 and 3. Infect. Immun. 68:2998-3001.

29. Wesson, C.A., et al. 1998. Staphylococcus aureus Agr and Sar global regulators influence internalization and induction of apoptosis. Infect. Immun. 66:5238-5243

30. Menzies, B.E., and Kourteva, I. 1998. Internalization of Staphylococcus aureus by endothelial cells induces apoptosis. Infect. Immun. 66:5994-5998.

31. Menzies, B.E., and Kourteva, I. 2000. Staphylococcus aureus alpha-toxin induces apoptosis in endothelial cells. FEMS Immunol. Med. Microbiol. 29:39-45.

32. Nuzzo, I., Sanges, M.R., Folgore, A., and Carratelli, C.R. 2000. Apoptosis of human keratinocytes after bacterial invasion. FEMS Immunol. Med. Microbiol. 27:235-240.

33. Tucker, K.A., Reilly, S.S., Leslie, C.S., and Hudson, M.C. 2000. Intracellular Staphylococcus aureus induces apoptosis in mouse osteoblasts. FEMS Microbiol. 
Lett. 186:151-156.

34. Jonas, D., et al. 1994. Novel path to apoptosis: small transmembrane pores created by staphylococcal alpha-toxin in T lymphocytes evoke internucleosomal DNA degradation. Infect. Immun. 62:1304-1312.

35. Zhang, B., Hirahashi, J., Cullere, X., and Mayadas, T.N. 2003. Elucidation of molecular events leading to neutrophil apoptosis following phagocytosis: cross-talk between caspase 8 , reactive oxygen species, and MAPK/ERK activation. J. Biol. Chem. 278:28443-28454.

36. Baba Moussa, L., et al. 1999. Discoupling the $\mathrm{Ca}(2+)$-activation from the pore-forming function of the bi-component Panton-Valentine leucocidin in human PMNs. FEBS Lett. 461:280-286.

37. Leist, M., Single, B., Castoldi, A.F., Kuhnle, S., and Nicotera, P. 1997. Intracellular adenosine triphosphate (ATP) concentration: a switch in the decision between apoptosis and necrosis. J. Exp. Med. 185:1481-1486.

38. Ferrari, D., Stepczynska, A., Los, M., Wesselborg, S., and Schulze-Osthoff, K. 1998. Differential regulation and ATP requirement for caspase- 8 and caspase- 3 activation during CD95- and anticancer drug-induced apoptosis. J. Exp. Med. 188:979-984.

39. Grassme, H., et al. 2000. CD95/CD95 ligand interactions on epithelial cells in host defense to Pseudomonas aeruginosa. Science. 290:527-530.

40. Rudi,J., et al. 1998. Involvement of the CD95 (APO-1/ Fas) receptor and ligand system in Helicobacter pylori-induced gastric epithelial apoptosis. J. Clin. Invest. 102:1506-1514.

41. Baran, J., et al. 2001. Fas (CD95)-Fas ligand interactions are responsible for monocyte apoptosis occurring as a result of phagocytosis and killing of Staphylococcus aureus. Infect. Immun. 69:1287-1297.

42. Gross, A., Jockel, J., Wei, M.C., and Korsmeyer, S.J. 1998. Enforced dimerization of BAX results in its translocation, mitochondrial dysfunction and apoptosis. EMBO J. 17:3878-3885.

43. Kluck, R.M., Bossy-Wetzel, E., Green, D.R., and Newmeyer, D.D. 1997. The release of cytochrome c from mitochondria: a primary site for Bcl-2 regulation of apoptosis. Science. 275:1132-1136.

44. Yang, J., et al. 1997. Prevention of apoptosis by Bcl-2: release of cytochrome $\mathrm{c}$ from mitochondria blocked. Science. 275:1129-1132.

45. Murphy, B.M., O’Neill, A.J., Adrain, C., Watson, R.W., and Martin, S.J. 2003. The apoptosome pathway to caspase activation in primary human neutrophils exhibits dramatically reduced requirements for cytochrome c. J. Exp. Med. 197:625-632.

46. Galmiche, A., et al. 2000. The N-terminal $34 \mathrm{kDa}$ fragment of Helicobacter pylori vacuolating cytotoxin targets mitochondria and induces cytochrome $c$ release. EMBOJ. 19:6361-6370.

47. Muller, A., et al. 2000. Targeting of the pro-apoptotic VDAC-like porin (PorB) of Neisseria gonorrhoeae to mitochondria of infected cells. EMBO J. 19:5332-5343.

48. Muchmore, S.W., et al. 1996. X-ray and NMR structure of human Bcl-xL, an inhibitor of programmed cell death. Nature. 381:335-341.

49. Mannella, C.A. 1998. Conformational changes in the mitochondrial channel protein, VDAC, and their functional implications. J. Struct. Biol. 121:207-218.

50. Rudel, T., et al. 1996. Modulation of Neisseria porin (PorB) by cytosolic ATP/GTP of target cells: parallels between pathogen accommodation and mitochondrial endosymbiosis. Cell. 85:391-402.

51. Gauduchon, V., et al. 2004. Neutralization of Staphylococcus aureus Panton Valentine leukocidin by intravenous immunoglobulin in vitro. J. Infect. Dis. 189:346-353.

52. Braun, J.S., et al. 1999. Neuroprotection by a caspase inhibitor in acute bacterial meningitis. Nat. Med. 5:298-302.
53. Hotchkiss, R.S., et al. 2000. Caspase inhibitors improve survival in sepsis: a critical role of the lymphocyte. Nat. Immunol. 1:496-501.

54. Hotchkiss, R.S., et al. 1999. Prevention of lymphocyte cell death in sepsis improves survival in mice. Proc. Natl. Acad. Sci. U. S. A. 96:14541-14546.

55. Nesin, M., et al. 1990. Cloning and nucleotide sequence of a chromosomally encoded tetracycline resistance determinant, tetA(M), from a pathogenic, methicillin-resistant strain of Stapbylococcus aureus. Antimicrob. Agents Chemother. 34:2273-2276.

56. Arnaud, M., Chastanet, A., and Debarbouillé, M. 2004. New vector for efficient allelic replacement in naturally nontransformable, low-GC-content, gram-positive bacteria. Appl. Environ. Microbiol. 70:6887-6891.

57. Guillet, V., Keller, D., Prévost, G., and Mourey, L. 2004. Crystallization and preliminary crystallographic data of a leucotoxin S component from Staphylococcus aureus. Acta Crystallogr. D. Biol. Crystallogr. D60:310-313.

58. Kyte, J., and Doolittle, R.F. 1982. A simple method for displaying the hydropathic character of a protein. J. Mol. Biol. 157:105-132.

59. Kayagaki, N., et al. 1999. Involvement of TNF-related apoptosis-inducing ligand in human CD4+ T cellmediated cytotoxicity. J. Immunol. 162:2639-2647.

60. Koopman, G., et al. 1994. Annexin V for flow cytometric detection of phosphatidylserine expression on B cells undergoing apoptosis. Blood. 84:1415-1420.

61. Zamzami, N., et al. 1995. Sequential reduction of mitochondrial transmembrane potential and generation of reactive oxygen species in early programmed cell death. J. Exp. Med. 182:367-377.

62. Ekert, P.G., Silke, J., Hawkins, C.J., Verhagen, A.M., and Vaux, D.L. 2001. DIABLO promotes apoptosis by removing MIHA/XIAP from processed caspase 9 . J. Cell Biol. 152:483-490. 